\title{
Tomás de Aquino, la justicia social y el derecho al trabajo en Colombia
}

\author{
Carlos Alberto Cárdenas Sierra*
}

Fecha de recibido: 6 de febrero de 2006

Fecha de aprobación: 14 de marzo de 2006

\section{RESUMEN}

Desde la perspectiva tomista se critica la legislación laboral colombiana reciente que tiende, por efecto de la globalización, a la flexibilización de la relación de trabajo, de tal manera que ésta se traslada gradualmente desde el ámbito del derecho social al ámbito del derecho privado.

\section{PALABRAS CLAVE}

Tomás de Aquino, juristas-teólogos del siglo XVI, justicia protectiva, justicia social, flexibilización, relación de trabajo, "dilectio socialis".

\section{ABSTRACT}

From the thomist perspective is criticized the recent labor legislation of Colombia that tends, because of the globalization, to a flexibility of the labor relationship in such a way that this is transferred gradually from the ambit of social law to private law.

\section{KEY WORDS}

Thomas Aquinas, Jurists and Theologians of the XVI Century, protective justice, social justice, flexibility, labor relationship, "dilectio socialis".

Docente de la Facultad de Derecho de la Universidad Santo Tomás, adscrito a la línea de investigación "Pensamiento ético, político y jurídico de Santo Tomás y tradición dominicana", reconocido por COLCIENCIAS en 2004, actualmente en categoría A. El presente trabajo es producto del proyecto de investigación sobre la "Jusfilosofía tomista en diálogo con la jusfilosofía contemporánea". 


\section{El concepto de trabajo}

La tradición aristotélico-tomista ${ }^{1}$ identifica en la acción humana cuatro dimensiones o dinamismos: el comprender (esfera vital de la adecuación de las cosas y el entendimiento que tiene por objeto lograr una visión racional estructurada); el obrar (esfera vital de la vida de relación que tiene por objeto la construcción del carácter); el hacer (esfera vital que tiene por objeto la transformación del entorno); y el comunicar (esfera vital de la interacción a través de los diversos lenguajes). Como el hombre no se desdobla, toda actividad humana actualiza al mismo tiempo estas cuatro dimensiones con énfasis en la que reclama la circunstancia.

La palabra "trabajo" hace referencia al esfuerzo humano aplicado a la producción de las cosas necesarias para vivir bien. La circunstancia general implícita en el significante trabajo es la de la adecuación del entorno. Esto ubica esta actividad, especialmente, en la esfera vital del hacer. Mas, no se trata de una operación desprovista de finalidad, como sucede, por ejemplo, con el pasatiempo. El aspecto teleológico, en la idea de trabajo, direcciona siempre la fuerza humana hacia algo productivo. Algo que redunde en bienestar para el individuo o para todos.

Hay, por lo menos, tres grados de producción y de bienestar: el básico, en donde lo producido tiende a satisfacer necesidades primarias (alimento, techo, vestido, etc.); el lúdico, en donde lo producido tiende a satisfacer necesidades relacionadas con los estados psicológicos de la alegría (juguetes, elementos deportivos, etc.); y el tecnológico, en donde lo producido amplía las posibilidades de bienestar y reduce las distancias comunicativas entre los seres humanos. Los gra- dos de producción-bienestar pueden integrarse como cuando se construye una casa de familia con dependencias de recreo. Es seguro que al lado de este aspecto positivo de estas gradaciones encontramos también el negativo: como la producción de armas. Aquí es donde las otras dimensiones de la acción (conocer, obrar, comunicar) como pesos y contrapesos entran en la escena para regular o reorientar la finalidad del trabajo.

Decimos que el trabajo es actividad consciente que distingue a los seres humanos de los animales o las máquinas porque se trata de una actividad razonada que tiende a la búsqueda del bienestar externo del hombre. Y por esta vía se pueden alcanzar también bienes espirituales.

La búsqueda de fines individuales y colectivos que deben concretarse en cosas que transforman el entorno humanizándolo es lo que distingue al trabajo del juego, del deporte o del "pasatiempo". El trabajo es especialmente actividad transitiva que persigue un resultado externo distinto de la actividad misma. Mientras que el juego, el deporte o el pasatiempo tienen un fin en sí mismo. Actividad exteriorizada y fines se confunden. Se puede decir que estas actividades son improductivas pues no se pretende la transformación o acomodación del entorno a las necesidades humanas.

El encuentro entre el hombre y el entorno natural no ha sido fácil, siempre ha implicado esfuerzo cognoscitivo, actividad fatigosa y aún hasta sufrimiento. Los términos más frecuentes no solamente aluden a la actividad y sus productos, sino que connotan algo penoso, fatigoso, pesado, asociado inmediatamente con la necesidad del descanso o momentos de ocio. 


\section{El concepto aquiniano de trabajo}

Tomás de Aquino (TdA), hacia 1244, resuelve romper con los intereses feudales (mundo de servidumbre) y asumir los intereses de los burgos (mundo de libertades, trabajo agremiado y comercio), es decir, cuando abandona la idea de llegar a ser abad benedictino y prefiere hacerse fraile dominico, llamado a convertirse en universitario, vocero de las preocupaciones de los distintos gremios, observa nítidamente dos tipo de relaciones de trabajo: la que subordinaba la totalidad de la vida y de la actividad productiva de los siervos (con "capitis deminutio" casi máxima) y la que subordinaba la actividad productiva de los artesanos (protegidos por las "cartas de libertad" comunales).

Es tan importante en ese innovador siglo XIII el nuevo tipo de relación de trabajo entre artesano libre y gremio, que Tomás y su maestro Alberto Magno se sienten obligados a reflexionar sobre el significado del trabajo en la vida humana y sobre las relaciones de justicia entre trabajo y retribución. Ambos se van haciendo conscientes de que la riqueza de las ciudades y de los reinos se va constituyendo no solamente por la abundancia de bienes naturales y de dinero, sino también por el trabajo y sus productos ${ }^{2}$.

El término latino utilizado por Tomás para referirse al trabajo es "laborare", con todo lo que este término denota y connota de esfuerzo, de consagración, de cuidado, y también de incomodidad y aun de sufrimiento. No obstante, los esfuerzos de quien "labora" no son inútiles: se "labora" para ganarse la vida; se "labora" en el parto y se trae un niño... Escribe en la Suma Teológica $^{3}$ que la naturaleza no adaptó al hom- bre a ningún biótopo ni le dio medios de defensa o abrigo como a los demás animales, pero que "en su lugar posee de modo natural la razón y las manos". Poner en acción razón y manos para proveerse, en eso consiste el "laborare", actividad transitiva propia de seres humanos. Aunque la palabra a veces se usa metafóricamente para referirse a fenómenos naturales, los animales (burros, mulas, caballos, bueyes) propiamente no "laboran". Esto implica razón y manos.

Las tendencias básicas -pautas de ley natural- son: la autoconservación, la unión entre los sexos y la educación de los hijos, el conocimiento de la verdad y la vida en sociedad ${ }^{4}$. Tales exigencias radicales de supervivencia humana implican abundancia y circulación de cosas, que es preciso tomar de la naturaleza (cultivándola) o que hay que crear. Y eso es "laborare". Así, pues, el trabajo implica por naturaleza estas notas: es personal, en cuanto la energía que opera (razón y manos); y es necesario, por cuanto el fruto del trabajo es indispensable a la persona para sostén y desarrollo de su vida con todas sus implicaciones. Por tanto, "laborar", en sentido aquiniano, es ocuparse en hacer algo con objeto de adquirir las cosas necesarias para los usos diversos de la vida y, sobre todo, para la propia conservación.

\section{Justicia y trabajo en Tomás de Aquino}

La vida social no es posible sin la dinámica de las tres justicias: la general, que convoca a todos los asociados a aportar al "bien común"; la distributiva, que exige repartir bienes personales desde el "bien común"; y la conmutativa, que regula los intercambios de bienes entre las personas. $\mathrm{Na}$ die puede aportar al "bien común" si no tiene

TOMÁS DE AQUINO. Comentario a la Política. L. I, lecc.7.

Cf. TdA. Suma Teológica, I, q. 76, a. 5.

Cf. TdA. Suma Teológica, I-II, q. 94, a. 2. 
con qué, si no es sujeto activo de justicia conmutativa; y nadie es sujeto activo de esta justicia si la sociedad no le asegura, por la justicia distributiva, medios de vida o la fuente de esos medios, que es el trabajo. $Y$ el trabajo y los medios de vida no son, en concepto aquiniano, meros "derechos subjetivos" sin objeto concreto ("ius ad rem"): trabajo no es "derecho al trabajo", sino tener efectivamente trabajo; "derecho a la vivienda", no es "derecho a comprarla", sino tenerla. El "derecho" es, ante todo, no una norma ni una facultad-"para" reconocida, sino una "cosa". Tomás explica que "ius" significa prioritariamente "cosa debida" o "cosa justa" para poder vivir. La norma es apenas "medida de cosas", y la facultad es algo que nace de tener "cosas".

Las cosas ("iura"), las cosas justas ("iusta") indispensables para vivir y "vivir bien", según Tomás, están pre-repartidas por el hecho natural de haber nacido como ser humano. Si así se nació, así se debe vivir. Y si así se debe vivir, pues no puede faltar lo necesario para lograrlo ("iura, iusta"). Claro está que cada uno debe buscar esas "cosas" y hacerlas en concreto "suyas". Y para ello debe poder "laborare". Es lo mínimo que la sociedad no puede negar a nadie. Y el "laborare" será el título para que cada cual se pueda convertir en acreedor y exigir que se le dé "lo suyo". El derecho ("ius, iura, iusta") es acto primero; la justicia, que debe dar, es acto segundo. Escribe Aquino: "Siendo el acto de justicia dar a cada uno lo que es suyo, al acto de la justicia precede otro acto por el cual alguien se apropia de algo, ...pues uno trabajando ("Iaborando") merece que se convierta en suyo lo que el retribuyente le da por acto de justicia" ${ }^{5}$.
En la época de Tomás, la estatua de la Justicia aún no aparecía con venda sobre los ojos. Era todavía la dama de ojos abiertos del jurista Aulo Gelio (s. II), vigilante de las desigualdades, dispuesta a proteger al más débil. Por eso Aquino pensaba que era preciso flexibilizar las rigideces de la ley con la "equidad" ${ }^{\text {, }}$, atendiendo los derechos naturales de quienes resultaban excluidos de alcanzar "vida buena", porque ni siquiera tenían oportunidad de "laborare". La "equidad" o "epiqueya", por otra parte, exigía atenerse a las situaciones reales de los sujetos de la relación jurídica, más allá de la "lex", pues "el derecho no es la ley, sino la realidad misma" ("ius non est lex, sed ipsa res") $)^{7}$.

Aquino consideraba que el "laborare" debía tener una retribución "justa", lo cual significaba que debía corresponder a la "estimación común" (communis aestimatio) de la opinión pública, que en justicia distributiva recurría a sopesar la cantidad de trabajo como medida del salario, algo así como "a igual trabajo, igual salario" -TdA dice que se llama "justo lo que según cierta igualdad corresponde a otro: por ejemplo, la remuneración debida por un servicio prestado" ${ }^{8}-$, y, además, debía ser suficiente para garantizar al trabajador una vida digna como padre de familia, de tal manera que pudiera "atesorar" y llegar a ser "propietario", tanto para la "educatio" (nutrición e instrucción) de sus hijos como para asegurarles herencia. No obstante, su idea de la propiedad no era la quiritaria romana: su trabajador-propietario debía considerarse una especie de gerente, obligado a conservar las cosas de modo apropiado y ponerlas a disposición de sus semejantes, especialmente de quienes contribuían a "atesorar". La propiedad-función aquiniana, como

TdA. Contra Gentiles. L. 2, cap. 28.

6 ST. II-II, 120.

7 ST. II-II, 57.

8 ST. II-II, 57, 1. 
"potestad de administrar y distribuir", es mecanismo de justicia distributiva.

Aunque el trabajo está orientado a los objetos externos, se manifiesta como revelación de la vida interna del hombre. Por ello, el "laborator" debe conocer los fines de su acción creativa. En el trabajo se desarrolla la persona desde sí misma. Sin embargo, el trabajo no puede absorber toda la vida del hombre. No se vive para trabajar, sino que se trabaja para "vivir bien" o "se trabaja para tener ocio", como decía Aristóteles. El "laborator" no es un Sísifo, condenado de por vida a llevar la roca a la cumbre, sin descanso y sin íntimo fruto. La actividad productiva debe permitir el descanso para la recuperación de fuerzas, el tiempo libre para el juego y la diversión (eutrapelia), los tiempos no subordinados para la actividad intelectual, estética, amorosa, festiva, lúdica, religiosa (es decir, "el ocio", que no es sinónimo de pereza ni de ociosidad). De ahí los tiempos celebratorios del calendario cristiano, que van haciendo cesura en el año laboral, contra los apetitos del ánimo de lucro.

\section{Derecho laboral y la Escuela de Salamanca}

Los tomistas de la Escuela teológico-jurídica de Salamanca, en el siglo XVI, junto con los teólogos misioneros, también de estirpe tomista, lograron, tras lucha tenaz, que esas ideas de Aquino se desarrollasen y tuviesen prolongaciones normativas en la Legislación de Indias. En ésta se reconoce que los indios son hombres, que son libres, que no pueden ser reducidos a esclavitud, que sus relaciones de trabajo no admiten subordinación total... El jurista Antonio Rumeu de Armas descubre que especialmente el Libro VI de la Legislación indiana constituye un "código laboral".

De 1512 a 1549, se libra en torno a las encomiendas la batalla de la libertad de los indios. En 1512, las leyes de Burgos traducen el reclamo de los misioneros que denuncian la esclavitud indiana y sacuden las convicciones de los peninsulares con la pregunta desafiante de fray Antón de Montesinos, que hablaba en nombre de la comunidad de dominicos de la Española: " $i$ Aquestos no son hombres?". En 1542, las Leyes Nuevas de Carlos V recogen tanto lo prescrito en la Bula "Sublimis Deus", expedida por el Papa cinco años antes, a solicitud de los misioneros dominicos fray Bartolomé de Las Casas, fray Rodrigo de Ladrada y fray Julián Garcés, con la astuta ayuda de fray Bernardino de Minaya, como los planteamientos doctrinales de Soto y Vitoria en la Universidad de Salamanca. Y en 1549, nuevas leyes reglamentan la libertad de trabajo y prohíben, al mismo tiempo, la obligatoriedad de los servicios personales, de sabor feudal.

El libro VI de la legislación de Indias, que hace parte de la Recopilación de 1680, permite inferir el régimen de protección que los Maestros de Salamanca imaginaban para los indios cuya situación les describían sus amigos y cofrades misioneros. Es muy probable que ellos se inspiraran también en la experiencia de Bartolomé de las Casas en la costa venezolana, quien, inspirado en Alberto Magno y Tomás de Aquino, consagraba, antes de Adam Smith y de Carlos Marx, la importancia del trabajo productivo como fuente de la riqueza frente a las convicciones comunes en su época sobre la preponderancia de la mera acumulación de oro, plata y piedras preciosas como clave de la riqueza personal y nacional, convicciones que impulsaban los proyectos de conquistadores, soldados y encomenderos. De Las Casas trazó un plan audaz para una nueva economía indiana: las familias de los nativos aprenderían a trabajar la tierra a ejemplo de familias de labradores peninsulares con quienes deberían convivir pacíficamente en zonas protegidas de los desmanes de los conquistadores. Se trataba de crear en estas tierras improductivas una 
nueva clase campesina trabajadora, capaz de autoabastecerse y de exportar excedentes a la Península. Como el proyecto -iniciado en Cumaná, en el norte de Venezuela- terminó en rotundo fracaso, porque chocaba con los intereses de conquistadores y encomenderos, que se encargaron de soliviantar la hostilidad indígena, De Las Casas optó por emprender una prolongada lucha a favor de los derechos de los indios sometidos a trabajo servil o esclavo. Esta empresa implicó la implantación gradual de leyes protectoras encaminadas a regular la relación de trabajo. Para que la temprana utopía lascasiana de Cumaná alcanzara éxito, fue preciso esperar a las "Reducciones" jesuitas del Paraguay.

Lo cierto es que, al leer el libro VI de la Recopilación, lo que aparece de bulto es que la estructura de las instituciones allí consagradas tiene gran analogía con los sueños lascasianos. Los salmanticenses tomistas, que saben unir los hechos con el derecho, y que saben adecuar tanto los principios tomistas de los tratados De la Ley y De Justicia como los principios del derecho canónico, romano y derecho civil peninsular, habían aprendido a distinguir entre lenguaje y realidad, entre el universal hombre o humano y el hombre singular de carne y hueso: el individuo perceptible al que le duelen o le pasan cosas y sufre o goza.

La actividad doctrinal de los Salmanticenses se hace valer especialmente en 1542 y en 1549: Ios legisladores están pendientes del ejercicio del "ius publici respondendi" de los Maestros que, como Vitoria y Soto, tienen "autoridad" no solamente en la Universidad, sino también ante el monarca, ante la Corte y ante el Consejo de Indias. Soto como vocero de los misioneros- ha proclamado a los cuatro vientos la dignidad y los derechos de los pobres, la necesidad de su protección, la li- bertad del nuevo pobre que es el indio, la igualdad de derechos entre peninsulares e indios, y las libertades de conciencia y de trabajo de los indios, su derecho a la instrucción y al descanso, el rechazo a la esclavitud, etc.

La estructura general de la recopilación de las leyes de indias funciona hacia el centro dinámico articulador de las relaciones de trabajo y la libertad de los indios defendida por la figura del "protector de los indios" con fines individuales y comunitarios.

Se destacan de esta normatividad las siguientes regulaciones: la libertad del trabajo, la contratación, el salario, la jornada de trabajo, el trabajo doméstico, el trabajo de mujeres y niños, los riesgos en el trabajo, un régimen para trabajos especiales (coca, chacras, minas, mita) y un régimen de protección y previsión social. Además se establecía también el trabajo colectivo para intereses comunes. Estas son importantes conquistas laborales de los misioneros defensores de los indios in situ y de los maestros justeólogos de Salamanca.

En particular se consagraba que no se podía contratar para trabajar a más de 10 leguas de la residencia, ni por un plazo superior a un año, ni para realizar trabajos a destajo, ni para trabajar más de 8 horas en fortificaciones y fábricas, ni más de 7 horas en minas; ni se podía cargar a los indios mayores de 18 años con más de 2 arrobas, ni obligar a trabajar a menores de 18 años, etc. Y el jornal debía ser pagado en dinero ("reales"). Y el descanso dominical era sagrado e inviolable ${ }^{9}$.

La herencia doctrinal tomista sobre vida social y trabajo continuó viva en el seno de la Iglesia católica y se ha convertido, en especial desde León XIII, en inspiración medular de la Doctrina Social

ROMEU DE ARMAS, Antonio. Código del Trabajo del indígena americano. Madrid: Cultura Hispánica, 1953, passim. 
de la Iglesia. Fue preciso esperar a fines del siglo XIX para que muchos líderes sociales, religiosos, políticos - gracias al empuje de los movimientos socialistas, especialmente del marxismo- se preocuparan por empezar a concretar instituciones de "derecho del trabajo".

La relación laboral, desde la legislación de indias, no puede seguir regulada por las normas del derecho privado basadas en relaciones de coordinación. En el siglo XIX, conscientes de eso, se comienza a hablar de justicia social, en donde el aparato estatal entra a intervenir para proteger a la parte más débil de la relación de trabajo. Es así como gradualmente, con la intervención de doctrinas de diferentes posturas axiológicas (Doctrina social y Marxismo, por ejemplo) se va construyendo un derecho social. Al respecto Gustav Radbruch precisaba: "Se mantiene en pie, ciertamente, la tradicional distinción entre derecho privado y derecho público, pero en vez de la nítida separación de antes surgen ahora nuevas zonas jurídicas, como el derecho del trabajo y el derecho económico, que no pueden ser enclavadas, en conjunto, en ninguno de aquellos campos, sino que forman más bien una mezcla o combinación de normas de derecho privado y derecho público"10.

\section{Trabajo subordinado en Colombia}

En Colombia las relaciones de trabajo urbanas se distribuyen entre el empleo, el subempleo y el pseudo-empleo. El primero pertenece al sector de la economía formal; $y$, los otros dos, al sector de la economía informal. El resto del "empleo urbano" se reparte entre el sector formal privado y el sector público.

La relación costo laboral y progreso empresarial llevó a que la administración Betancur contratara una investigación para diagnosticar y establecer perspectivas y políticas sobre la realidad del trabajo subordinado en el país. En 1987, de manera conjunta, el SENA, el Departamento Nacional de Planeación y la Contraloría General de la República publicaron en dos volúmenes los informes de la "Misión Chénery", que recogían los resultados de esa investigación.

Del informe podemos resaltar estos puntos: 1) características generales del mercado de trabajo en Colombia; 2) relación ingresos-pobreza; 3) el tráfico laboral se concreta en: informalidad, empleo público, trabajo temporal y subcontratación; 4) el impacto de la legislación laboral del sector privado sobre el empleo.

Para la "Misión Chénery", los obstáculos para la creación de empleo eran: 1$)$ la legislación laboral inflexible; 2) falta de la mecanización del proceso productivo; 3 ) el régimen de cesantías; 4) la inflexibilidad para despedir trabajadores antiguos; 5) Ios impuestos a la nómina; 6) la indemnización por despido injusto; 7) régimen de convenciones colectivas; 8 ) fuero sindical.

La "Misión Chénery", al estudiar separadamente el régimen prestacional del sector privado o carga laboral no salarial, consideró que los obstácuIos más grandes para la creación de nuevos puestos de trabajo eran: a) compensación por días no trabajados (vacaciones, dominicales, festivos); b) régimen de seguridad social (pensiones de jubilación, enfermedad profesional, maternidad, invalidez, vejez y muerte, subsidio familiar, bienestar familiar, seguros o beneficios extralegales de jubilación, salud, etc.); c) complementos salariales (cesantías retroactivas e intereses, prima de servicios, primas de antigüedad, de vacaciones y otras extralegales, recargos de horas extras, festivos y nocturnos, subsidio de transporte, vestido y

10 RADBRUCH, Gustav. Introducción a la filosofía del derecho. México: FCE, 1974, p. 93. 
calzado de trabajo, gastos de entierro, fondo de vivienda, auxilio de educación, matrimonio, etc.); d) costos de enganche y despido (período de prueba, SENA, costos de entrenamiento en el trabajo, indemnización, pensión-sanción, acción de reintegro).

La "Misión" consideró "que el sistema prestacional colombiano es normal" comparándolo con los sistemas de otros países. Además, parte de la carga prestacional había sido desplazada hacia los mismos trabajadores o a los consumidores. Por otra parte, la cobertura efectiva de esos derechos era limitada, pues las prestaciones legales completas cobijaban únicamente a un $28 \%$ de "la población ocupada del país". Con base en lo anterior se concluyó que la carga prestacional no era el problema fundamental para la creación de empleo, pues la crisis industrial y la recesión de los 80 resultaban más determinantes cuantitativa y cualitativamente.

El equipo investigativo de la "Misión", no obstante la conclusión anterior, recomendó la reducción drástica de los costos laborales y de prestaciones sociales, la modificación del sistema de cesantías, la eliminación de la retroactividad de las mismas, la abolición de la acción de reintegro para los trabajadores con más de 10 años de servicios, la limitación de la pensión-sanción y de jubilación y la adopción de nuevos niveles para los recargos por trabajo suplementario. No pocas de las recomendaciones fueron recogidas por la leyes 50 de 1990, 100 de 1993 y 789 de 2002, que, además, legalizaron las prácticas patronales de privatización de la relación de trabajo, introducidas especialmente por los empleadores norteamericanos: la utilización de contratistas independientes e intermediarios en los grandes procesos industriales, comerciales y agropecuarios -modelo que llegó a las actividades del sector público, sobre todo en las empresas industriales y comerciales del Estado y en las de economía mixta-; los trabajadores ya no aparecen ligados por contrato de trabajo, sino por contrato de obra; el contrato de prestación de servicios se aplica cada vez más frecuentemente.

La mencionada Ley 50 de 1990 quebró la espina dorsal del Código Sustantivo del Trabajo, conquista de grandes luchas laborales del pasado nacional: la seguridad y estabilidad que implicaba la relación de trabajo como garantía de futuro. Ésta Ley, inspirada en el "veintiochismo" de los empleadores norteamericanos, modificó el contrato a término fijo que no podía ser inferior a un año, y posibilitó los contratos a término fijo desde 1 día hasta 3 años, para favorecer la movilidad de la mano de obra, que circula como mercancía de empleador en empleador.

La "apertura económica", que impone el proceso de "globalización" (término propuesto por los economistas norteamericanos para caracterizar su propio modelo económico), exigió la reestructuración industrial y ésta implica la "flexibilización" o desmonte del aparato protectivo de la "relación de trabajo". De lo contrario, "no se podría competir en el mercado mundial", "el mercado de abundancia para todos", guiado por la "mano invisible" de Adam Smith.

En 15 años de "flexibilización" o pérdida de alcance de la normatividad del trabajo, gracias al paquete de reformas legislativas sustantivas (leyes $50 / 90,731,755$ y $789 / 02$ ) y la del procedimiento (L. 712/01) constituyen una legislación laboral que favorece el sub-empleo y deslaboraliza la relación de trabajo; además, tanto la jurisdicción laboral como el Ministerio de Protección Social ven reducidas sus funciones protectivas, ya que miles de trabajadores salen del ámbito protectivo del derecho social para ubicarse sin amparo en el mundo del derecho privado. Los trabajadores siguieron prestando sus servicios personales en continuada subordinación y dependencia (por unos pocos días o unos pocos meses) a cambio de contraprestaciones irrisorias. Los juristas "labora- 
listas" ven reducido su campo de trabajo y empiezan a especializarse como abogados "patronalistas" o a pasarse a las filas de los privatistas.

Las formas protectivas de vinculación estables para Ios trabajadores fueron sustituidas por sistemas de gestión coordinada en los que desaparece la figura del empleador, reemplazada por intermediarios, y se desvirtúa el elemento de la relación laboral relacionado con la prestación personal del servicio -es una empresa la que presta el servicio directamente a través de un órgano-. Se impone el modelo de contrato civil o comercial, de acuerdo con los cuales el trabajador ya no se somete, como desigual y necesitado de protección, sino que "se compromete" como igual libremente, con plena autonomía, a quien le paga su servicio, si no es que se le considera "socio" como sucede en las cooperativas de trabajo asociado. Por otra parte, se generalizan distintas formas de "flexibilización laboral" que han venido imponiéndose en formas jurídicas de contrato a término fijo, trabajo a domicilio, teletrabajo (a través de internet), agencias de colocación o empleo, servicio temporal; $y$ las formas indirectas de prestación de servicios, con énfasis en la relación comercial, que dan origen a la "tercerización" (subcontratación de servicios) o "outsourcing".

Así, han proliferado las EST (empresas de servicios temporales), que contratan directamente trabajadores "en misión" para realizar labores en beneficio de un tercero (usuario); las CTA (cooperativas de trabajo asociado), que vinculan el trabajo personal de los socios y sus aportes económicos a la cooperativa; las ACE (agencias intermediadoras de colocación o empleo), que contratan oferentes y demandantes de mano de obra para llenar vacantes; las EAT (empresas asociativas de trabajo), cuyos asociados aportan capacidad laboral por tiempo indefinido. En las EST, el trabajador "en misión" está protegido con restricciones por el régimen laboral ordinario; en las CTA, el trabajador-cooperado no está protegido por el régimen laboral; en las ACE, el trabaja- dor no tiene vínculo con la colocadora; en las EAT, el trabajador tiene vínculo puramente comercial... Trabajadores, que antes se vinculaban mediante contrato laboral, ahora se desempeñan temporalmente a través de alguna de estas formas indirectas de prestación de servicios.

\section{La relación de trabajo migra al ámbito del derecho privado}

En nuestro derecho colombiano, la "relación de trabajo" es un tecnicismo exclusivamente laboral (como en la doctrina italiana o mejicana) referido al hecho de la prestación de un trabajo subordinado. Ante ese hecho, el sistema jurídico-laboral reconoce el "deber ser", "relación de trabajo", que implica efectos no sujetos a la libre voluntad de los vinculados. La "relación de trabajo" es una situación jurídica objetiva creada automáticamente por la iniciación de la actividad transitiva subordinada. Sin duda que la prestación del trabajo proviene de actos de voluntad de trabajador $y$ empleador, pero los efectos protectivos que se producen derivan directamente de la ley y de los contratos colectivos.

Puede decirse que la "relación de trabajo" es una creación jurídico-laboral que consiste en el conjunto de derechos y obligaciones que surgen para trabajadores y empleadores por el simple hecho (intersubjetivo) de la prestación subordinada del servicio. Tal relación hace compatibles las dos autonomías: ampliando la del trabajador más allá de lo negociado y restringiendo la del empleador mediante prohibiciones por "razones de orden público". Por el hecho del ingreso del trabajador a la empresa, se aplica a las dos autonomías un estatuto objetivo preexistente, que funciona como una providencia supraindividual relacionante. No son las voluntades las que se relacionan, sino la evidencia factual. De ahí la primacía de la realidad sobre las formalidades. Como decía el realista Tomás de Aquino, "el derecho no es la norma, sino la cosa misma" ("ius non est lex, sed ipsa res"). 
En nuestra legislación se presume que toda "relación de trabajo" personal está regida por un contrato de trabajo (art. 24 CST). Basta demostrar el supuesto, o sea la existencia de la relación interpersonal para que se presuma regida o ejecutada mediante contrato individual de trabajo. Para demostrar lo contrario, la carga de la prueba le corresponde al empleador. Consiste la prueba en acreditar la inexistencia de la subordinación específica, o sea, la no dependencia continuada del trabajador a órdenes o disposición del empleador. La ley 50/90, sin embargo, intentó infirmar la presunción anterior, pero la Corte Constitucional corrigió el intento 8 años más tarde.

El énfasis en la contractualidad de la "relación de trabajo" y la institución del "contrato de trabajo" como tal se debió a la necesidad de salir al paso de la práctica patronal de hacer suscribir al trabajador contratos de naturaleza civil o comercial para encubrir la realidad de la continuada subordinación y eludir así los derechos y garantías legales como consecuencia automática de la prestación del servicio.

Al facilitarse el auge de relaciones de trabajo civiles a partir de la Ley 50/90, se ha tendido a legitimar la individualización de las relaciones al margen de las figuras normativas generales, creando amplios espacios para lo singular atípico. Se coloca en primer plano al trabajador concreto como individuo "liberado de trabas laborales", con la autonomía del sujeto de relaciones civiles o comerciales, apartado de las previsiones supraindividuales del CST. Esto conduce a que se enfrenten dos clases de trabajadores: uno tipificado en el Código laboral, frente al atípico, cuya voluntad se concierta libremente con la libre empresa.

En el Estado neoliberal, al debilitarse éste, se debilita también la fuerza del derecho público y de su mecanismo protector, que es el derecho social: entonces la relación de trabajo tiende a migrar hacia el ámbito fuerte del derecho privado. Y los trabajadores, "iguales ante la ley", quedan en libertad y sin "trabas laborales" para realizar su actividad transitiva y ganarse la "vida", que podría tener remedio si se cambia la jerarquía de valores y de necesidades en los centros de poder que determinan la suerte de la humanidad.

\section{Hacia una propuesta de solución tomista: "dilecto socialis"}

Tomás de Aquino, inspirado en Aristóteles, había hablado de "justicia general o legal", de "justicia distributiva" y de "justicia conmutativa". En cuanto "general", reguladora de la totalidad de las relaciones intersubjetivas para el bien común; en cuanto "legal", referida al diseño "arquitectónico" del bien común y a su traducción en orden político y jurídico. La "distributiva", reguladora de las distribuciones que el bien común debe hacer para equilibrar los bienes personales o particulares. La "conmutativa", reguladora de los intercambios de bienes entre los miembros de la sociedad.

En el siglo XIX se recoge la tradición semántica sin significante preciso y se le da el nombre de "justicia social" a un cuarto tipo de justicia que junto a las aristotélico-tomistas, compromete no solamente al Estado, sino a todos los sectores sociales, especialmente a los centros de control y decisión, con fines de inclusión social, de integración de los sectores no participantes o marginados, para que no haya excluidos de los beneficios colectivos mínimos, necesarios para llevar una vida humana digna. En este caso, la nueva forma de justicia resulta heredera de esa forma de justicia que reclamaron los teólogos y misioneros del siglo XVI, y que dio origen a instituciones de inclusión y de "protección" de los marginados de entonces: los descendientes de los precolombinos. La justicia social de hoy fuerza a generar respuestas de inclusión-integración, teniendo en cuenta que tal "inclusión-integración" no podrá realizarse en la "alienación" o negación de los 
proyectos de vida de los "incluidos", convirtiéndolos en componentes funcionales de intereses privados o públicos. Se tratará siempre de inclusión-integración-promoción de personas, no de inclusión-integración de impersonales "fuerzas de trabajo" o "recursos humanos".

Se ha entendido por "justicia social" este dar a quienes no tienen de hecho lo que su dignidad exige, con el fin de que pasen a ser sujetos activos del "nosotros" colectivo. Todos los excluidos son acreedores, y tanto el Estado como los miembros activos de la convivencia son deudores en justicia, obligados a "dar" o "hacer" con miras de "inclusión-integración". Y como esto no se puede dejar a la mera buena voluntad, el Estado debe potenciar la "función social" de todo derecho económico y el ejercicio de las "justicias" clásicas: es preciso, de continuo, proyectar políticamente el bien común con intención "inclusiva" y traducirlo legalmente; es indispensable distribuir y redistribuir con criterio "incluyente"; es necesario regular la justicia conmutativa para que opere con intención social y se torne también distributiva.

El derecho laboral, como forma del derecho social, concreta, traduce de manera directa la función de la "justicia social": es un derecho de inclusión-integración que subordina las autonomías privadas de los empleadores y protege las autonomías privadas en desventaja de quienes deben vender y subordinar por un salario su fuerza de trabajo. Doble protección brinda este derecho social: vigila la relación de trabajo, con presunciones a favor del trabajador, y propicia el desarrollo del sindicato, sujeto laboral colectivo, vigilante de los derechos de los trabajadores. El término mismo "sin-dicato" alude a la posibilidad de organizarse (syn) y a la finalidad de la organización: defensa del derecho (diké).

No obstante, el derecho laboral no alcanza a cubrir la totalidad de las posibilidades y exigencias del "derecho social": termina convertido en un derecho protector para un sector que vive entre la pobreza relativa y cierta suficiencia de bienes. Como mecanismo de inclusión-integración, ha tenido éxito en la defensa de quienes entraron en relación directa con el aparato productivo y de servicios: miles de trabajadores han podido sobrevivir con el mínimo de medios de vida, y miles han podido acumular un mediano patrimonio que los convierte en sujetos competentes para el intercambio privado. El reto contemporáneo es que el derecho laboral evolucione hacia una "protección mínima suficiente" que facilite nuevas "inclusiones" laborales para los marginados, los desempleados, las nuevas generaciones de fuerza de trabajo disponible, convirtiéndose en avanzada de nuevo del derecho social.

El derecho laboral actual está decayendo en su forma e intención clásicas y puede desaparecer, sustituido por una legislación "flexible" que incluya-integre-proteja de manera inédita a la mayoría o a todos los que necesitan ofrecer su actividad transitiva. ¿Esa legislación "flexible" será apta para garantizar la seguridad estable que todo trabajador espera?, ¿o se tratará de esas nuevas normas que brindan protección inestable y a medias, sin auténtica garantía de la "libertad exterior" (medios de vida) del trabajador? Por una nueva legislación "flexible" y "des-laboralizada" abogan hoy las transnacionales, las multinacionales y todos los empleadores, que aspiran a suprimir "contratos laborales" y a valerse solamente de "contratos de servicios" o de contratos de "outsourcing". De esta manera, se simula un "amplio" cubrimiento laboral, pero se trata de un fenómeno semejante al del consumidor de artículos higiénicos: se usan y se van desechando.

El ejercicio del derecho social supone lo que Tomás de Aquino denominaba "dilectio socialis" o "dilección social", disposición afectiva favorable a la construcción del bien común, semejante a la "affectio societatis" que implica el "contrato de sociedad". Tal "dilectio socialis" deberá animar los 
movimientos políticos de resistencia contra el espíritu "globalista" depredador, dinamizado por el afán de lucro de los grandes intereses privados mundiales, no compatible con la necesidad de proteger a todos, pues lo único que le importa es promover la "competitividad" entre economías nacionales desiguales. $Y$ ya se sabe que nada es "competitivo" en la producción y en el mercado si resulta costoso. La "flexibilidad" en producción y mercado busca desembarazarse de trabas jurídicas y de costos: del derecho laboral entrabador y de las seguridades de los trabajadores, que deben estar disponibles para ir y venir y sustituirse a bajo precio. Los trabajadores no son sujetos necesitados de medios de vida estables sino mercancías que deben circular a precio de mercado.

Lo muy malo de esta "competencia" inter-nacional, es que se trata de una maratón entre desiguales: atletas calificados del I Mundo, atletas más o menos entrenados del II Mundo, "atletas" desnutridos del III Mundo y atletas agónicos del IV Mundo. Como si se organizase una carrera "entre iguales" conformada por fortachones, ciegos, cojos, minusválidos de toda índole, niños y ancianos... Ya se sabe cuáles serán las economías rezagadas, que no podrán llegar a la meta. Se adivina qué podrá ocurrir con las naciones excluidas, cuyos aparatos productivos entrarán en recesión definitiva. ¿Qué pasará con los antiguos sujetos activos de la legislación laboral y los millones de sujetos que esperaban ingresar al mercado laboral para sobrevivir? La duda final es: ¿podrá sostenerse un mercado mundial sin consumidores? Al contrario de lo que piensa Beck, aquí no es posible una "participación individual-colectiva" porque los excluidos del consumo mundial no alcanzan a tener la carta de ciudadanía que los habilita para la "democracia directa" a través de la "papeleta de compra"11 en la construcción de una "sociedad cosmopolita".

Así como el actual derecho laboral se fue construyendo por la presión de las movilizaciones y las luchas sindicales de los trabajadores, se espera que surja un nuevo derecho laboral, impulsado por las nuevas y tremendas luchas de las grandes masas de potenciales consumidores en cesantía forzada. Ocurrirá algo semejante a lo que ocurrió en la crisis del capitalismo de los años 20: los productores necesitaron consumidores y éstos necesitaron seguir viviendo. Se puede excluir a muchos durante todo el tiempo, pero no se puede excluir a todos durante todo el tiempo.

\section{BIBLIOGRAFÍA}

\section{AQUINO, TOMÁS DE}

\section{A) Sumas}

Suma teológica. Traducción Dirigida por los Regentes de Estudios de las Provincias Dominicanas de España. Madrid: BAC, 1994 (IV y V Tomos), 1990 (III Tomo), 1989 (II Tomo) y 1988 (I Tomo).

Suma Contra Gentiles. Texto latino al cuidado de la Orden de Predicadores con traducción y notas introductorias de Laureano Robles Carcedo, O.P., Adolfo Robles Sierra, O.P., y José M. de Garganta, O.P. Madrid: BAC, 1967, 2a. ed. (2 Tomos).

\section{B) Comentarios}

Tomás de Aquino y Pedro de Alvernia. Comentario a la Política de Aristóteles. Navarra (Pamplona): EUNSA, 2001 (traducción y prólogo de Ana Mallea, notas de Mallea y Celia A. Lértora).

$1 \quad$ Cf. Beck, Ulrich. ¿Qué es la globalización? Paidós, 1989, p. 106. 
Comentario a la Ética a Nicómaco de Aristóteles. Navarra (Pamplona): Eunsa, 2a. ed., 2001 (traducción de Ana Mallea, estudio preliminar y notas de Celia A. Lértora Mendoza).

ARIZA, Alberto. Fray Bartolomé de Las Casas. Bogotá: Kelly, 1974.

ANZOÁTEGUI, Victor Tau, ¿Qué fue del derecho Indiano? Bs. As: Abeledo-Perrot, 1982.

BELDA P., Juan. La Escuela de Salamanca. Madrid: BAC, 2000.

BECK, Ulrich. ¿Qué es la globalización? Barcelona: Paidós, 1989.

CARRO, Venancio. Los teólogos juristas españoles. Salamanca: BTE, 1951.
CONTRALORÍA GENERAL DE LA REPÚBLICA - SENA. El problema Laboral colombiano. Bogotá, 1987.

PÉREZ GARCíA, Miguel y ARAGÓN DE PÉREZ, Victoria. "Flexibilización laboral y outsourcing". Bogotá: Dike, 1999.

RADBRUCH, Gustav. Introducción a la filosofía del derecho. México: FCE, 1974.

RUMEU DE ARMAS, Antonio. Código del indígena Americano. Madrid: $\mathrm{CH}, 1953$.

SILVA ROMERO, Marcel (Comp.). El derecho laboral que hereda el nuevo milenio. Bogotá: UNAL, 1999.

ZAVALA, Silvio. Filosofía de la Conquista. México: FCE, 1977. 